\title{
Multi-Toxic Endpoints of the Foodborne Mycotoxins in Nematode Caenorhabditis elegans
}

\author{
Zhendong Yang ${ }^{1,2}$, Kathy S. Xue ${ }^{2}$, Xiulan Sun ${ }^{1}$, Lili Tang ${ }^{2, *}$ and Jia-Sheng Wang ${ }^{2}$ \\ Received: 22 September 2015; Accepted: 13 November 2015; Published: 2 December 2015 \\ Academic Editor: Paul Turner \\ 1 Synergetic Innovation Center of Food Safety and Nutrition, School of Food Science, Jiangnan University, \\ Wuxi, Jiangsu 214122, China; zdyang777@163.com (Z.Y.); sxlzzz@jiangnan.edu.cn (X.S.) \\ 2 Department of Environmental Health Science, University of Georgia, Athens, GA 30602, USA; \\ ksxue@uga.edu (K.X.); jswang@uga.edu (J.S.W.) \\ * Correspondence: ltang@uga.edu; Tel.: +1-706-542-9765; Fax: +1-706-542-7472
}

\begin{abstract}
Aflatoxins $\mathrm{B}_{1}\left(\mathrm{AFB}_{1}\right)$, deoxynivalenol $(\mathrm{DON})$, fumonisin $\mathrm{B}_{1}\left(\mathrm{FB}_{1}\right)$, $\mathrm{T}-2$ toxin $(\mathrm{T}-2)$, and zearalenone (ZEA) are the major foodborne mycotoxins of public health concerns. In the present study, the multiple toxic endpoints of these naturally-occurring mycotoxins were evaluated in Caenorhabditis elegans model for their lethality, toxic effects on growth and reproduction, as well as influence on lifespan. We found that the lethality endpoint was more sensitive for T-2 toxicity with the $\mathrm{EC}_{50}$ at $1.38 \mathrm{mg} / \mathrm{L}$, the growth endpoint was relatively sensitive for $\mathrm{AFB}_{1}$ toxic effects, and the reproduction endpoint was more sensitive for toxicities of $\mathrm{AFB}_{1}, \mathrm{FB}_{1}$, and $\mathrm{ZEA}$. Moreover, the lifespan endpoint was sensitive to toxic effects of all five tested mycotoxins. Data obtained from this study may serve as an important contribution to knowledge on assessment of mycotoxin toxic effects, especially for assessing developmental and reproductive toxic effects, using the C. elegans model.
\end{abstract}

Keywords: aflatoxin $\mathrm{B}_{1}$; Caenorhabditis elegans; deoxynivalenol; fumonisin $\mathrm{B}_{1}$; mycotoxins; T-2 toxin; zearalenone

\section{Introduction}

Mycotoxins are toxic secondary metabolites produced by fungi growing on agricultural commodities in the field or during storage $[1,2]$. These naturally-occurring mycotoxins display diverse chemical structures accounting for their differing biological properties and effects [3]. Depending upon their precise biochemical nature, they induced multiple toxic effects including carcinogenic, teratogenic, mutagenic, estrogenic, neurotoxic, and immunotoxic effects [4-6]. Spurred by the discovery of aflatoxins in the 1960s, more than 100 toxigenic fungi and in excess of 300 mycotoxins were identified worldwide [7]. The aflatoxins, fumonisins, ochratoxins, zearalenone (ZEA), and trichothecenes, such as deoxynivalenol (DON) and T-2 toxin (T-2) are the major foodborne mycotoxins of public health concerns $[6,8]$.

Aflatoxins represent a group of closely related difuranocoumarin compounds mainly produced by Aspergillus flavus, A. parasiticus, and four naturally-occurring aflatoxins $\left(\mathrm{B}_{1}, \mathrm{~B}_{2}, \mathrm{G}_{1}\right.$, and $\left.\mathrm{G}_{2}\right)$ were identified. Aflatoxins have been found in a variety of agricultural commodities, but the most pronounced contamination has been encountered in maize, peanuts, cotton seed, and tree nuts with the levels ranged from 0.11 to $4030 \mu \mathrm{g} / \mathrm{kg}$ [9]. Aflatoxin $\mathrm{B}_{1}\left(\mathrm{AFB}_{1}\right)$ is the most prevalent and toxic, and is also known as being one of the most potent genotoxic agents and hepatocarcinogens [10,11]. Developmental and reproductive toxic effects and immunotoxic effects of $\mathrm{AFB}_{1}$ have recently been recognized in the research field. 
Fumonisins are primarily produced by the fungi Fusarium verticillioides [12]. The most common fumonisin found in maize is fumonisin $\mathrm{B}_{1}\left(\mathrm{FB}_{1}\right)$, while fumonisins $\mathrm{B}_{2}$ and $\mathrm{B}_{3}\left(\mathrm{FB}_{2}\right.$ and $\left.\mathrm{FB}_{3}\right)$ are common co-contaminants. $\mathrm{FB}_{1}$ was mainly found in corn and corn products with the levels ranging from 0.01 to $330 \mathrm{mg} / \mathrm{kg}$ [13]. $\mathrm{FB}_{1}$ exposure was suggested to link to a broad spectrum of animal and human diseases, such as hepatocellular carcinoma and esophageal cancer in South Africa, China, and the Islamic Republic of Iran [14-18]. In addition to the carcinogenic property, $\mathrm{FB}_{1}$ exposure played a role in the occurrence of a cluster of neural tube defects along the Texas-Mexico border [19].

ZEA is mainly produced by Fusarium graminearum and is primarily contaminated maize but occurs in modest concentrations in wheat, barley, and sorghum, and concentrations in food ranged from 0.01 to $2909 \mathrm{mg} / \mathrm{kg}$ [20]. ZEA induces genotoxicity, immunotoxicity, developmental and reproductive toxicities, and tumorigenicity in various animal models [21,22]. Due to its structural similarity to estrogen, ZEA may bind to human estrogen receptors and elicit permanent reproductive tract alterations [23]. Studies also suggested that ZEA exposure was associated with a high incidence of primary liver cancer in animals and human and may contribute to the increasing occurrence of breast cancer.

DON and T-2 are trichothecene mycotoxins produced by many fungi genera and plants [24] and over 80 diverse compounds in structure were found [25]. DON is probably the most widely distributed Fusarium mycotoxin in cereals and its contamination was reported in various crops and processed grains with the range from 0.01 to $500 \mathrm{mg} / \mathrm{kg}$ [20]. T-2 has been reported in cereals in many parts of the world with the range from 0.01 to $40 \mathrm{mg} / \mathrm{kg}$, and it is formed in large quantities under the unusual circumstance of prolonged wet weather at harvest [26]. These two mycotoxins had significant pathophysiological effects in humans and animals because of their interference with protein synthesis [27]. DON and T-2 induced phosphokinase-mediated stress pathways, aberrantly activated proinflammatory gene expression, disrupted gastrointestinal function and growth hormone action, and caused cell death [28]. Acute exposures to high doses of T-2 or DON in experimental animals induced anorexia, diarrhea, and vomiting; moreover, at extremely high doses, lethal toxic effects were observed, including gastrointestinal hemorrhage, leukocytosis, circulatory shock, reduced cardiac output, and ultimately, death. Chronic exposure of animals to moderate doses impaired food intake, reduced weight gain, disrupted immune function, and caused developmental toxic effects [28].

Due to the widespread nature of toxigenic fungi in the environment, mycotoxins were considered as unavoidable contaminants in foods and feeds; therefore, one of the most effective measures to protect public health is to set up regulatory levels of these toxins. Well-defined toxic endpoints and mechanistic studies are the basis for establishing regulatory level and risk assessment. Although rodent-based assays have been the traditional models for toxicological studies, it is well-recognized that rodent assays are time consuming and expensive. Therefore, other in vivo or in vitro assays were introduced into toxicological field to take their advantages for rapid, inexpensive, and without concern of animal welfare issues. Although in vitro cell-based assays are commonly used, whole organism models are biologically relevant and allow observing both genomic alterations and phenotypic modifications. The nematode Caenorhabditis elegans (C. elegans), a popular model organism for genetic and developmental biology research [29], is now being recognized as an attractive invertebrate model for toxicological studies [30-35].

C. elegans is a free-living nematode that has some attractive properties, such as short life cycle (3-4 days), ease of culturing, and low cost. Its well-defined genome, completed cell lineage map, knockout $(\mathrm{KO})$ mutant libraries, and well established methodologies including mutagenesis, transgenesis, and RNA interference (RNAi) can provide a variety of options to manipulate molecular mechanisms. Furthermore, there is a high degree of conservation between C. elegans and mammalian species in processes controlling development, neurobiology, and stress responses [36]. For these unique features $C$. elegans met with the "Three R" requirements (replacement, reduction, and refinement) and has been extensively applied to toxicological fields in the recent years $[37,38]$. 
Nevertheless, there are fewer studies in the literature for studying toxic effects of foodborne mycotoxins in C. elegans. Evidence that could link C. elegans with mycotoxin toxicities in humans included the presence of CYP450 orthologue, which can metabolize $\mathrm{AFB}_{1}$ similar to in humans, as well as various orthologues of glutathione transferase, one of the most well-known phase II metabolic and detoxification mechanisms of $\mathrm{AFB}_{1}$. Furthermore, there is a high degree of conservation between C. elegans and mammalian species in processes controlling development, neurobiology, and stress responses, which allow us to explore molecular mechanisms of reproductive, developmental, and transgenerational effects of mycotoxins.

In this study, we investigated multiple toxic endpoints of common foodborne mycotoxins, $\mathrm{AFB}_{1}, \mathrm{DON}, \mathrm{FB}_{1}, \mathrm{~T}-2$, and ZEA with structures shown in Figure 1, in C. elegans model, including lethality, toxic effects on growth and reproduction as well as influence on lifespan. Data presented clearly demonstrated that $C$. elegans model can predict toxic effects of mycotoxins, and can use for mechanistic studies of mycotoxins-induced adverse health effects.

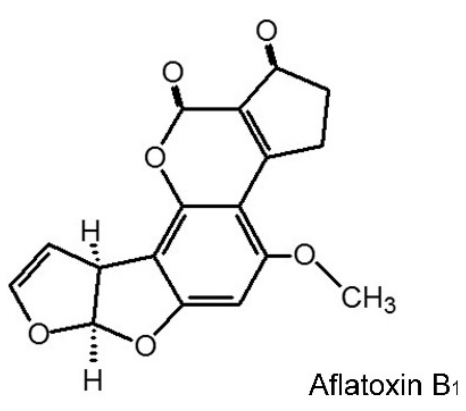<smiles>O=C1CCC/C=C/CCCC(=O)c2cc(O)cc(O)c2C(=O)O1</smiles>

Zearalenone<smiles>CC(=O)OCC12CC(OC(=O)CC(C)C)C(C)=CC1OC1C(O)C3(C)CC1(C)C32CO</smiles>

Figure 1. The structural formula of five mycotoxins.

\section{Results}

\subsection{Lethality}

The wild-type N2 strain was treated with various concentrations of tested mycotoxins for $24 \mathrm{~h}$ and their $\mathrm{LC}_{50}$ values were calculated and shown in Table 1. Lethality in control worms was less than $10 \%$ in all cases. The potency for lethality, as represented by $\mathrm{LC}_{50}$ values, in the wild-type N2 worms was $\mathrm{T}-2>\mathrm{AFB}_{1}>\mathrm{ZEA}>\mathrm{FB}_{1}>\mathrm{DON}$. Toxicity ranking based on $\mathrm{LC}_{50}$ is $\mathrm{T}-2(1 \mathrm{mg})>\mathrm{AFB}_{1}$ $(20 \mathrm{mg})>\mathrm{ZEA}(76 \mathrm{mg})>\mathrm{FB}_{1}(235 \mathrm{mg})>\mathrm{DON}(657 \mathrm{mg})$. 
Table 1. Lethality for wild-type N2 C. elegans treated with mycotoxins.

\begin{tabular}{cccccc}
\hline Mycotoxins & AFB1 & DON & FB1 & T-2 & ZEA \\
\hline $\mathrm{LC}_{50} \mathrm{mg} / \mathrm{L}$ & 20.47 & 656.67 & 235.62 & 1.38 & 75.79 \\
$95 \% \mathrm{CI}$ & $12.67-45.21$ & $435.96-1145.66$ & $79.07-640.142$ & $1.01-1.76$ & $5.83-985.03$ \\
\hline
\end{tabular}

\subsection{Toxic Effects on Growth}

As shown in Figure 2, five mycotoxins affected the growth of worm as indicated by body length, in dose-effect $(p<0.01)$ and time-effect manner $(p<0.05)$. Following $72 \mathrm{~h}$ exposure, $\mathrm{AFB}_{1}$ and T-2 at the concentration of $8 \mathrm{mg} / \mathrm{L}$ caused the greater growth-inhibitory effects, reaching $52.8 \%$ and $41.61 \%$ size reduction than untreated controls $(p<0.001)$. The median effective concentrations $\left(\mathrm{EC}_{50}\right)$ of $\mathrm{AFB}_{1}$ and the T-2 was $7.31 \mathrm{mg} / \mathrm{L}$ (95\%CI: 5.19-12.9 mg/L) and $16.91 \mathrm{mg} / \mathrm{L}(95 \% \mathrm{CI}: 9.31-59.81 \mathrm{mg} / \mathrm{L})$, which was 300 times lower than that of ZEA and $\mathrm{FB}_{1}$. Similar to what found in lethality testing, DON did not result in significant growth inhibitions at the concentrations between $50 \mathrm{mg} / \mathrm{L}$ and $800 \mathrm{mg} / \mathrm{L}$ (Table 2). The morphological changes caused by exposure to these five mycotoxins at $72 \mathrm{~h}$ were shown in Figure 3.
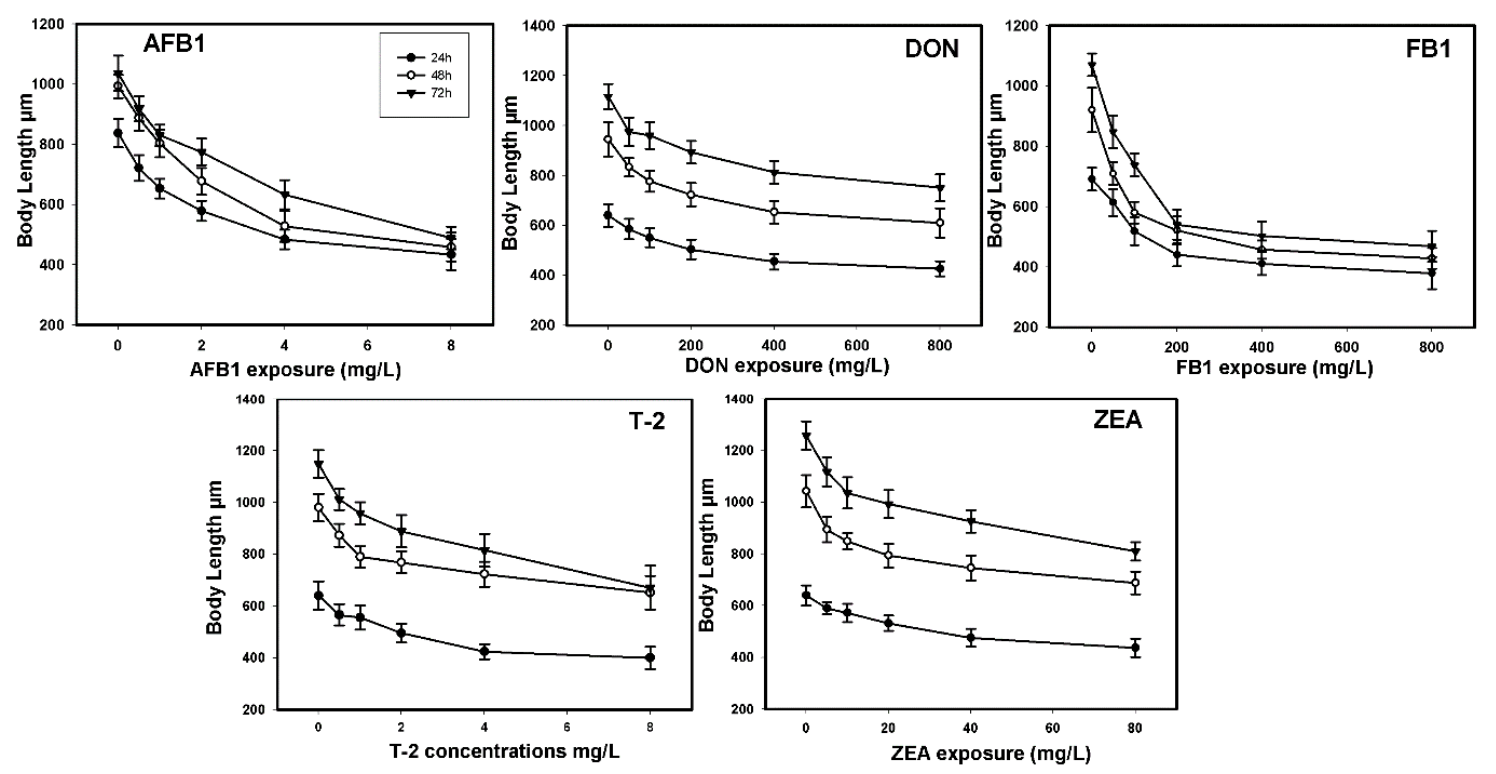

Figure 2. Effects on Body length of C. elegans exposed to mycotoxins at $24 \mathrm{~h}, 48 \mathrm{~h}$, and $72 \mathrm{~h}$.

Table 2. Toxic effects on growth and reproduction in N2 C. elegans following $72 \mathrm{~h}$ exposure to mycotoxins.

\begin{tabular}{|c|c|c|c|c|c|c|}
\hline \multirow[b]{2}{*}{ Mycotoxins } & \multicolumn{3}{|c|}{ Growth } & \multicolumn{3}{|c|}{ Reproduction } \\
\hline & $\mathrm{EC}_{50} \mathrm{mg} / \mathrm{L}$ & $\begin{array}{c}\text { Interval of } \\
\text { Confidence }(95 \%)\end{array}$ & $\begin{array}{c}\text { Ratio } \\
\mathrm{LC}_{50} / \mathrm{EC}_{50}\end{array}$ & $\mathrm{EC}_{50} \mathrm{mg} / \mathrm{L}$ & $\begin{array}{c}\text { Interval of } \\
\text { Confidence }(95 \%)\end{array}$ & $\begin{array}{c}\text { Ratio } \\
\mathrm{LC}_{50} / \mathrm{EC}_{50}\end{array}$ \\
\hline $\mathrm{AFB}_{1}$ & 7.31 & 5.19-12.50 & 2.80 & 1.69 & $1.38-2.04$ & 12.11 \\
\hline DON & 533.07 & $412.63-686.02$ & 0.49 & 487.28 & $311.15-515.90$ & 0.55 \\
\hline $\mathrm{FB}_{1}$ & 361.59 & $261.36-569.77$ & 0.65 & 25.63 & $19.63-31.77$ & 9.19 \\
\hline $\mathrm{T}-2$ & 16.96 & $9.13-59.81$ & 0.08 & 1.82 & $1.33-2.44$ & 0.76 \\
\hline ZEA & 314.19 & $129.74-860.21$ & 0.24 & 26.05 & $19.23-37.17$ & 2.90 \\
\hline
\end{tabular}




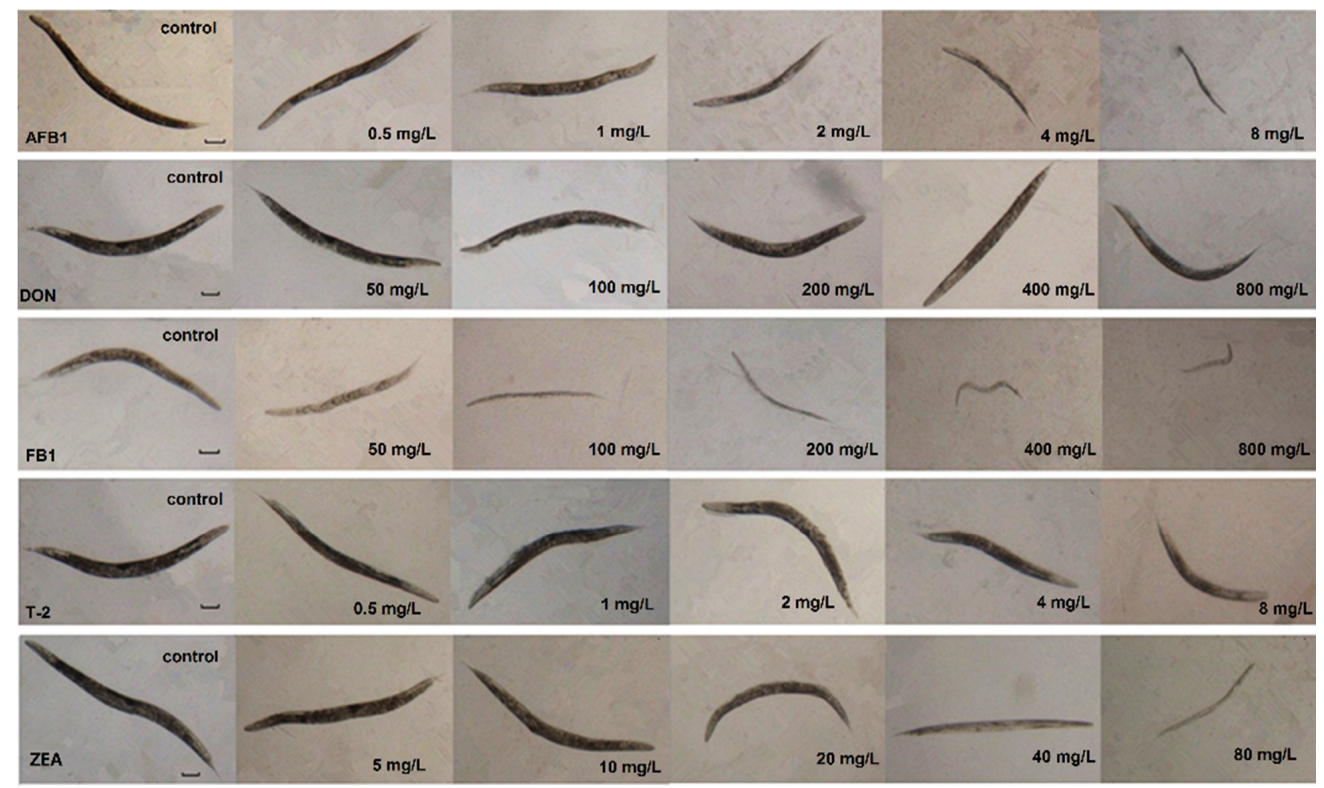

Figure 3. Morphological changes of adult C. elegans following $72 \mathrm{~h}$ exposure to mycotoxins (scale in $100 \mu \mathrm{m}$ for all panels).

\subsection{Toxic Effects of Reproduction}

Toxic effects on the N2 nematode reproduction, represented by number of offspring (brood size), as a function of mycotoxins concentration were plotted and shown in Figure 4. The average number of offspring for the untreated controls was $133 \pm 22$, comparable to previous studies [39]. The brood size was significantly reduced in at all tested concentrations for $\mathrm{AFB}_{1}(p<0.001)$, $\mathrm{DON}(p<0.05)$, $\mathrm{FB}_{1}(p<0.001), \mathrm{T}-2(p<0.001)$, and ZEA $(p<0.001)$, respectively, as compared to that in the untreated controls. Reproductive effects were commonly detectable at much lower concentrations of $\mathrm{FB}_{1}$, which suggested that $C$. elegans is a much sensitive model for testing reproductive toxic effects of $\mathrm{FB}_{1}$ as compared to other lethality and growth endpoints. The $\mathrm{EC}_{50}$ value with $95 \% \mathrm{CI}$ was estimated from the concentration-effect curve of each treated mycotoxin and listed in Table 2. The most sensitive mycotoxin is $\mathrm{AFB}_{1}$ with $\mathrm{EC}_{50}$ of $1.69 \mathrm{mg} / \mathrm{L}(95 \% \mathrm{CI}, 1.38-2.04 \mathrm{mg} / \mathrm{L})$.
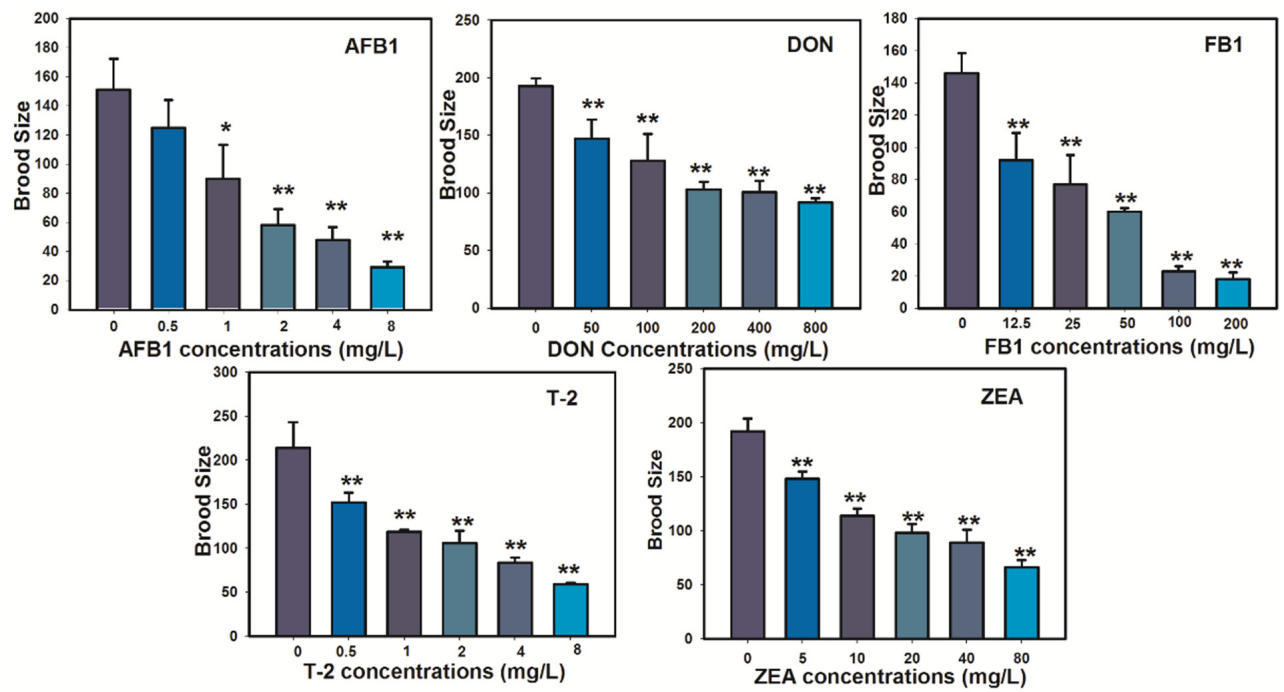

Figure 4. Toxic effects on brood size of N2 C. elegans following $72 \mathrm{~h}$ exposure to mycotoxins. 


\subsection{Influence on Lifespan}

The lifespan of N2 nematode treated with $10 \% \mathrm{LC}_{50}$ of five tested mycotoxins was independently recorded in order to test and compare the sensitivity of the assay. Mycotoxin treatment decreased lifespan and increased mortality rate, as illustrated by survival curve (Figure 5A), log cumulative hazard plots (Figure 5B), and data in Table 3. The survival curves of five mycotoxins were shifted to the left compared to untreated controls. The shape of the cumulative hazard plots, which reflected the rate of aging [40], and the y-intercept of the log cumulative hazard plots of five mycotoxins were significantly larger than that of untreated control $(p<0.0001)$ as assessed by OASIS. The mean lifespan exposed to $\mathrm{AFB}_{1}, \mathrm{DON}, \mathrm{FB}_{1}, \mathrm{~T}-2$, and ZEA significantly decreased from $17.26 \pm 0.47$ days to $4.85 \pm 0.19,5.19 \pm 0.35,5.66 \pm 0.26,3.83 \pm 0.29$, and $4.79 \pm 0.22$ days, respectively $(p<0.0001)$. As compared to the untreated control, the median lifespan time was significantly decreased by $70.59 \%$, $57.65 \%, 62.94 \%, 80.59 \%$, and $68.82 \%$, respectively.

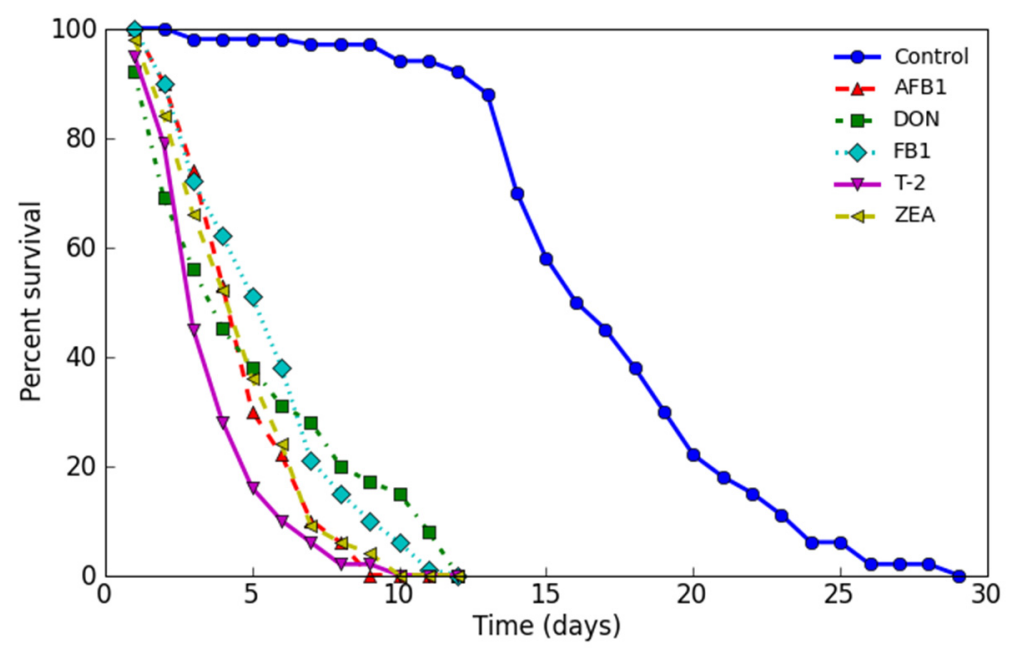

(A)

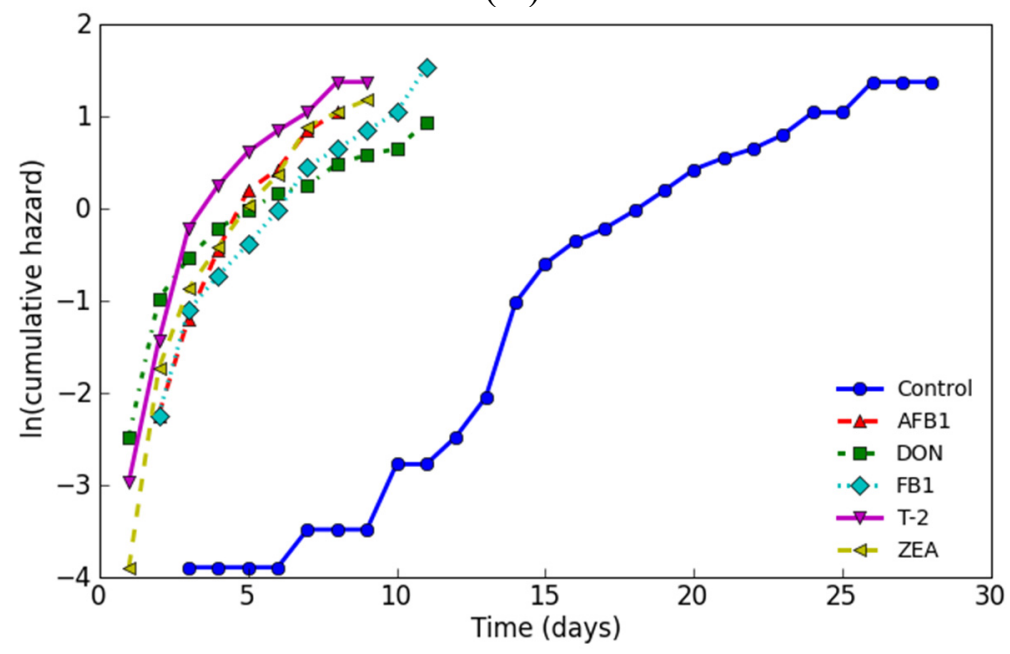

(B)

Figure 5. Survival curves (A) and log cumulative hazard plots (B) in N2 C. elegans treated with tested mycotoxins. 
Table 3. Influence on lifespan in N2 C. elegans treated with five tested mycotoxins.

\begin{tabular}{|c|c|c|c|c|c|c|c|c|c|c|}
\hline \multirow{2}{*}{ Name } & \multirow{2}{*}{$\begin{array}{c}\text { Dose } \\
\text { (mg/L) }\end{array}$} & \multirow{2}{*}{$\begin{array}{c}\text { No. of } \\
\text { Subjects }\end{array}$} & \multicolumn{3}{|c|}{ Estimated Mean } & \multicolumn{5}{|c|}{ Mortality (Days) } \\
\hline & & & Days & Std. & 95\% C.I. & $25 \%$ & $50 \%$ & $75 \%$ & $90 \%$ & $100 \%$ \\
\hline Control & 0 & 100 & 17.26 & 0.47 & $16.34-18.18$ & 14 & 16 & 20 & 24 & 29 \\
\hline $\mathbf{A F B}_{1}$ & 2.05 & 100 & 4.85 & 0.19 & $4.48-5.22$ & 3 & 5 & 6 & 7 & 9 \\
\hline DON & 65.67 & 100 & 5.19 & 0.35 & $4.50-5.88$ & 2 & 4 & 8 & 11 & 12 \\
\hline $\mathrm{FB}_{1}$ & 23.56 & 100 & 5.66 & 0.26 & $5.15-6.17$ & 3 & 6 & 7 & 9 & 12 \\
\hline $\mathrm{T}-2$ & 0.14 & 100 & 3.83 & 0.19 & $3.46-4.20$ & 3 & 4 & 5 & 6 & 10 \\
\hline ZEA & 7.58 & 100 & 4.79 & 0.22 & $4.36-5.22$ & 3 & 5 & 6 & 7 & 10 \\
\hline
\end{tabular}

\section{Discussion}

C. elegans has become a popular toxicity test organism, as well reviewed in details $[32,34,41]$. Much of the early work explored metal toxicity and used lethality as the major endpoint [42]. A wider variety of toxicants have been tested with C. elegans in recent years and more sophisticated sub-lethal endpoints have been developed, including parameters for growth and reproduction [30]. These types of endpoints were directly applied for evaluating environmental toxicants and used as an alternative method for mammalian testing [43]. There were fewer studies in the literature devoted to assess foodborne mycotoxins toxicity using C. elegans. Leung et al. [44] found that $\mathrm{AFB}_{1}$ induced toxic effects on growth and reproduction in C. elegans at the concentrations of 3, 30, and $100 \mu \mathrm{M}$, respectively. The progeny production and development rates of the nematode were significantly reduced when treated with DON at concentrations of 500 and $1000 \mathrm{mg} / \mathrm{L}$ [45]. Our present study showed that $\mathrm{LC}_{50}$ values of tested mycotoxins were at very high concentrations with the exception of T-2 $(1.38 \mathrm{mg} / \mathrm{L})$ and $\mathrm{AFB}_{1}(20.47 \mathrm{mg} / \mathrm{L})$. These findings were consistent with results using other model systems $[46,47]$. Compared to $\mathrm{LD}_{50}$ or $\mathrm{LC}_{50}$ values obtained from other model systems such as rats, fish, and human cells in the literature $[1,6,48,49]$ similar acute toxic response was found between rats and $C$. elegans for T-2. Similar or less acute toxic response for $\mathrm{AFB}_{1}$ was found in C. elegans $(20 \mathrm{mg} / \mathrm{L})$ as compared to values in rats $(2.7-17.9 \mathrm{mg} / \mathrm{L})$. C. elegans model is more sensitive for ZEA and less sensitive for $\mathrm{DON}$ as compared to $\mathrm{LD}_{50}$ in rodent model. It is hard to make conclusion for $\mathrm{FB}_{1}$ because no $\mathrm{LD}_{50}$ is available in rodents.

Following $72 \mathrm{~h}$ exposure, five mycotoxins had significant inhibitory effects on growth and reproduction endpoints of the nematode. Similar to what found for $\mathrm{LC}_{50}, \mathrm{AFB}_{1}$ and $\mathrm{T}-2$ had greater inhibitive effects than other tested mycotoxins on growth and reproduction. DON had minimal effects as compared to other four mycotoxins. The $\mathrm{LC}_{50}$ and $\mathrm{EC}_{50}$ (growth and reproduction) values (Table 2) were compared to evaluate the sensitivity of these toxic endpoints. As anticipated, large differences between lethality values and effective concentrations of growth or reproduction were found. In the case of $\mathrm{AFB}_{1}$, the $\mathrm{LC}_{50} / \mathrm{EC}_{50}$ ratio was 2.8 for growth and 12.11 for reproduction, which indicated that the $\mathrm{EC}_{50}$ of growth and reproduction values are more sensitive than the $\mathrm{LC}_{50}$ value. Thus, endpoints of growth and reproduction would be much more sensitive indicators of $\mathrm{AFB}_{1}$ toxicity than endpoints of lethality. Same cases for reproductive toxicity in $\mathrm{FB}_{1}$ and ZEA were found. On contrary, the lethality endpoint was more sensitive for T-2 than other mycotoxins and none of these three endpoints was sensitive for DON. Findings in our study were consistent with the reports in other species [50].

Traditionally, the lethality assay was a standard toxicity assay of C. elegans model, and the advantage of the assay was the relative ease in scoring worms' mortality and analysis. However, some mycotoxins so far tested, e.g., DON, were not very sensitive to the lethality endpoint, because mycotoxins are secondary metabolites of fungi and their toxic effects cumulated over a period of time [6] in addition to their different target organs and mode of actions. The less sensitive to DON was also observed in the earthworm [50].

Lifespan, rather than physiological indicators, is resulted from complex interactions between genetic, environmental, and stochastic factors and can provide critical insights into the entire life 
cycle affected by xenobiotics, including mycotoxins. As shown in our data, all five tested mycotoxins could result in shortening lifespan and increase mortality rate in C. elegans. The median lifespan time was significantly decreased following treatment with mycotoxins. These results suggested that influence on lifespan may be a specific endpoint for testing toxic effects of environmental toxicants like mycotoxins. In comparison with most of the other species currently used, lifespan assessment with C. elegans has been simplified and is easy to detect using a microscope, and to analyze with the established software [35]. In summary, we evaluated multiple endpoints for testing mycotoxin toxicities. Lethality endpoint was more sensitive for T-2 toxicity. The toxicity ranking for $\mathrm{LC}_{50}$ is $\mathrm{T}-2$ $(1 \mathrm{mg} / \mathrm{L})>\operatorname{AFB} 1(20 \mathrm{mg} / \mathrm{L})>\mathrm{ZEA}(76 \mathrm{mg} / \mathrm{L})>\mathrm{FB}_{1}(235 \mathrm{mg} / \mathrm{L})>\mathrm{DON}(657 \mathrm{mg} / \mathrm{L})$. Reproduction endpoint was more sensitive for toxicities of $\mathrm{AFB}_{1}, \mathrm{FB}_{1}$, and $\mathrm{ZEA}$. The ranking for reproduction: $\mathrm{AFB}_{1}(2 \mathrm{mg} / \mathrm{L})=\mathrm{T}-2(2 \mathrm{mg} / \mathrm{L})>\mathrm{ZEA}(26 \mathrm{mg} / \mathrm{L})=\mathrm{FB}_{1}(26 \mathrm{mg} / \mathrm{L})>\mathrm{DON}(487 \mathrm{mg} / \mathrm{L})$. The growth endpoint was also sensitive for $\mathrm{AFB}_{1}$ toxicity. The ranking for growth: $\mathrm{AFB}_{1}(7 \mathrm{mg} / \mathrm{L})>\mathrm{T}-2(17 \mathrm{mg} / \mathrm{L})$ $>$ ZEA $(314 \mathrm{mg} / \mathrm{L}) \geqslant \mathrm{FB}_{1}(362 \mathrm{mg} / \mathrm{L})>\mathrm{DON}(533 \mathrm{mg} / \mathrm{L})$. Moreover, the lifespan endpoint was sensitive to test toxic effects of all five mycotoxins. Data obtained from this study may serve as an important contribution to knowledge on evaluation of toxic effects of mycotoxins using C. elegans model, especially for assessing developmental and reproductive toxic effects of mycotoxins exposure in humans and animals.

\section{Experimental Section}

\subsection{Materials}

Mycotoxins selected for this study, including aflatoxin $\mathrm{B}_{1}$, deoxynivalenol, fumonisin $\mathrm{B}_{1}, \mathrm{~T}-2$ toxin, and zearalenone, were purchased from Sigma-Aldrich Chemical Co. (St. Louis, MO, USA). Purity of each toxin $(95 \%-99 \%)$ was tested with the appropriate analytical tools (HPLC, LC/MS, and GC/MS). Stock solutions were made with dimethylsulfoxide (DMSO) and kept under argon. Worms used in the present study, wild-type Bristol (N2), and E. coli strain OP50 were purchased from the Caenorhabditis Genetics Center (Minneapolis, MN, USA). All the worms used in this research were hermaphrodites. Worms growth medium (NGM) was made as previously described by Brenner [29]. All other chemicals and reagents were purchased commercially at the highest degree of purity available.

\subsection{Mycotoxins Exposures}

Five mycotoxins in stock solutions were diluted to different concentrations of test solutions. Three- to four-day old worms were dispensed into each well of a 12-well plate. Each well contained a mixture of $990 \mu \mathrm{L}$ complete K-medium, $10 \mu \mathrm{L}$ test solution, and OP50. The 1\% DMSO was found not affecting nematode growth or reproduction (data not shown). The exposure concentrations were selected based on preliminary lethality assays or solubility testing in complete K-medium with $1 \%$ DMSO, e.g., $\mathrm{AFB}_{1}$ had solubility limits of $\sim 50 \mathrm{mg} / \mathrm{L} \mathrm{K}$-medium.

\subsection{Lethalality Assay}

All worms were cultured at $20^{\circ} \mathrm{C}$ in Petri dishes. Lethality tests were performed on the three-day old wild-type worm for $24 \mathrm{~h}$ exposure to different concentrations of mycotoxins using methods described by Donkin and Williams [51]. Briefly, each test consisted of five concentrations plus a control, in which $10 \pm 1$ worms ( 30 worms for each concentration) were transferred to 12-well tissue culture plates containing $1 \mathrm{~mL}$ of the test solution in each of five wells. Mycotoxins solutions were prepared in $\mathrm{K}$-medium $(0.051 \mathrm{M} \mathrm{NaCl}$ and $0.032 \mathrm{M} \mathrm{KCl})$ [52], because worms suffer osmotic stress in deionized water. At the end of the exposure period, worms were counted and scored as live or dead under a microscope; they were judged to be dead if they did not respond to touch using a small, metal wire. All experiments were repeated for three times and the $\mathrm{LC}_{50}$ values were derived through a Probits analysis. 


\subsection{Measurement of Growth Endpoint}

Growth was assessed by measuring change in body length over a $72 \mathrm{~h}$ exposure period. The synchronized L-2 worms were used to develop at $20{ }^{\circ} \mathrm{C}$ either in control or five mycotoxins at different concentrations in K-medium with food. After exposure $72 \mathrm{~h}, 20$ worms were mounted into a glass pad containing 10\% formalin solution. Body length analysis (head to tail) was performed using an Olympus SZX9 microscope (Olympus America Inc. Center Valley, PA, USA) and Infinify analyze software (V5.0.2, Lumenera Corporation, Ottawa, ON, Canada, 2009). Three independent experiments were performed and, for each experiment, at least 20 control and treated worms were analyzed.

\subsection{Measurement of Reproductive Endpoint}

Reproduction was tested using the $72 \mathrm{~h}$ assays described by Dhawan et al. [42]. The test solutions consisted of different concentrations of $\mathrm{AFB}_{1}(0-8 \mathrm{mg} / \mathrm{L})$, or DON $(0-800 \mathrm{mg} / \mathrm{L}), \mathrm{FB}_{1}(0-800 \mathrm{mg} / \mathrm{L})$, T-2 (0-8 mg/L), ZEA (0-80 mg/L), respectively. One adult worm from an age-synchronized culture was placed in each $1 \mathrm{~mL}$ of test solution. Three wells were used for each concentration and exposed under the same conditions as described for the growth test. Three days later, the number of offspring at all stages beyond the eggs was determined [39]. For each test concentration and control, the average number of progeny from three wells was obtained for each test replicate, and the testing was repeated three times.

\subsection{Life-Span Experiment}

Lifespan analysis was conducted at $20{ }^{\circ} \mathrm{C}$ as described previously [53]. Synchronized young adult worms were placed on NGM agar plates and treated with $10 \% \mathrm{LC}_{50}$ of five tested mycotoxins and $0.1 \mathrm{mg} / \mathrm{mL}$ of 5-fluorodeoxyuridine (5-FUDR, Sigma, St. Louis, MO, USA) which was used to block progeny development [54]. Control experiments indicated that 5-FUDR did not affect worms' lifespan. Worms were transferred to fresh treatment plates every other day, and scored every day by gentle prodding with a platinum wire to test for live or dead worms. Those had ceased pharyngeal pumping and failed to move, even after repeated prodding, were scored as dead and removed from the plates. Worms that had crawled off onto the sides of the plate and died away from the agar were censored. A minimum of 100 worms was counted and scored per condition per experiment. Lifespan was defined as the time elapsed from when worms were put on treatment plates to when they were scored as dead. Three independent life-span studies were performed.

\subsection{Statistical Analysis}

The concentration-response relationships for lethality, growth, reproduction, and lifespan were generated from three independent replicate tests. The median lethal concentration $\left(\mathrm{LC}_{50}\right)$ and median effective concentration $\left(\mathrm{EC}_{50}\right.$, concentration producing a $50 \%$ reduction in body size or offsprings compared to control) with $95 \%$ confidence intervals (CI), were calculated using logistic regression. Response variables that were not normally distributed were transformed by logarithmic to improve normality. Generalized Linear Models (GLMS) was used to evaluate the significant difference among treatments and between all treatment levels and the control. The SAS 9.4 (SAS Institute, Cary, NC, USA) was used for data analysis and a $p$-value of 0.05 or less was considered to be statistically significant.

To determine the effects of experimental treatments on survival, a comprehensive comparison of survival datasets between an experimental group and a control group was analyzed using OASIS (online application of survival analysis, http://sbi.postech.ac.kr/oasis) [49]. The average survival time was obtained by using log-rank test, whereas those of a specific time point can be obtained by using Fisher's exact test [13]. If two data sets at $90 \%$ mortality show no statistically significant, 
the weighted log-rank test was used instead of Log-rank test, which developed by Fleming and Harrington [48] and was sensitive to early differences.

\section{Conclusions}

We evaluated multiple toxic endpoints for five common foodborne mycotoxins. Lethality endpoint seemed more sensitive for T-2 toxicity. Reproduction endpoint was more sensitive for toxicities of $\mathrm{AFB}_{1}, \mathrm{FB}_{1}$, and $\mathrm{ZEA}$. Growth endpoint was also sensitive for $\mathrm{AFB}_{1}$ toxicity. Moreover, lifespan endpoint was sensitive to test toxic effects of all five mycotoxins. Data obtained from this study suggests $C$. elegans model can serve as a good model organism for evaluation of toxic effects of mycotoxins, especially for assessing developmental and reproductive toxic effects.

Acknowledgments: This study was partially supported by research grants, CA 94683 and CA 90997 (to J.S.W.), from National Cancer Institute, National Institutes of Health and the research contract, ECG-A00-13-00001-00 (to J.S.W. and L.T.), via Peanut CRSP from United States Agency for International Development.

Author Contributions: Zhendong Yang and Kathy S. Xue carried out the experiments and analyzed the data. Xiulan Sun, Lili Tang, and Jia-Sheng Wang conceived and designed the study. Zhendong Yang, Lili Tang and Jia-Sheng Wang wrote and revised the manuscript.

Conflicts of Interest: The authors declare no conflict of interest.

\section{References}

1. Cole, R.J.; Cox, R.H. Handbook of Toxic Fungal Metabolites; Academic Press: New York, NY, USA, 1981.

2. Wogan, G.N. Mycotoxins. Annu. Rev. Pharmacol. 1975, 15, 437-451. [CrossRef] [PubMed]

3. Ciegler, A. Mycotoxins: Occurrence, chemistry, biological activity. Lloydia 1975, 38, 21-35. [PubMed]

4. Groopman, J.D.; Donahue, K.F. Aflatoxin, a human carcinogen: determination in foods and biological samples by monoclonal antibody affinity chromatography. J. Assoc. Off. Anal. Chem. 1988, 71, 861-867. [PubMed]

5. Newberne, P.M. Mycotoxins: Toxicity, carcinogenicity, and the influence of various nutritional conditions. Environ. Health Perspect. 1974, 9, 1-32. [PubMed]

6. Wu, F.; Groopman, J.D.; Pestka, J.J. Public health impacts of foodborne mycotoxins. Annu. Rev. Food Sci. Technol. 2014, 5, 351-372. [CrossRef] [PubMed]

7. Sharma, R.P.; Salunkhe, D.K. Mycotoxins and phytotoxins; CRC Press: Boca Raton, FL, USA, 1991.

8. Stoev, S.D. Foodborne mycotoxicoses, risk assessment and underestimated hazard of masked mycotoxins and joint mycotoxin effects or interaction. Environ. Toxicol. Pharmacol. 2015, 39, 794-809. [CrossRef] [PubMed]

9. International Agency for Research on Cancer (IARC). Aflatoxins. In Some Traditional Herbal Medicines, Some Mycotoxins, Naphthalene and Styrene; Monogr Eval Carcinog Risks Hum: Lyon, France, 2002; Volume 82, pp. 171-300.

10. Kensler, T.W.; Roebuck, B.D.; Wogan, G.N.; Groopman, J.D. Aflatoxin: A 50-year odyssey of mechanistic and translational toxicology. Toxicol. Sci. 2011, 120 (Suppl 1), S28-S48. [CrossRef] [PubMed]

11. Wogan, G.N.; Kensler, T.W.; Groopman, J.D. Present and future directions of translational research on aflatoxin and hepatocellular carcinoma. A review. Food Addit. Contam. Part A 2012, 29, 249-257. [CrossRef] [PubMed]

12. Joint FAO/WHO Expert Committee on Food Additives (JECFA). Fumonisins (addendum). In Safety Evaluation of Certain Food Additives and Contaminants; World Health Organization: Geneva, Switzerland, 2012; pp. 325-754.

13. International Agency for Research on Cancer (IARC). Fumonisin $\mathrm{B}_{1}$. In Some Traditional Herbal Medicines, Some Mycotoxins, Naphthalene and Styrene; Monogr Eval Carcinog Risks Hum: Lyon, France, 2002; pp. 301-366.

14. Marasas, W.F.; Riley, R.T.; Hendricks, K.A.; Stevens, V.L.; Sadler, T.W.; Gelineau-van Waes, J.; Missmer, S.A.; Cabrera, J.; Torres, O.; Gelderblom, W.C.; et al. Fumonisins disrupt sphingolipid metabolism, folate transport, and neural tube development in embryo culture and in vivo: A potential risk factor for human neural tube defects among populations consuming fumonisin-contaminated maize. J. Nutr. 2004, 134, 711-716. [PubMed] 
15. Shephard, G.S.; van der Westhuizen, L.; Sewram, V. Biomarkers of exposure to fumonisin mycotoxins: A review. Food Addit. Contam. 2007, 24, 1196-1201. [CrossRef] [PubMed]

16. Sun, G.; Wang, S.; Hu, X.; Su, J.; Huang, T.; Yu, J.; Tang, L.; Gao, W.; Wang, J.S. Fumonisin B $_{1}$ contamination of home-grown corn in high-risk areas for esophageal and liver cancer in China. Food Addit. Contam. 2007, 24, 181-185. [CrossRef] [PubMed]

17. Sun, G.; Wang, S.; Hu, X.; Su, J.; Zhang, Y.; Xie, Y.; Zhang, H.; Tang, L.; Wang, J.S. Co-contamination of aflatoxin $\mathrm{B}_{1}$ and fumonisin $\mathrm{B}_{1}$ in food and human dietary exposure in three areas of China. Food Addit. Contam. Part A 2011, 28, 461-470. [CrossRef] [PubMed]

18. World Health Organization (WHO). Fumonisin $\mathrm{B}_{1}$. In Environmental Health Criteria 219; World Health Organization: Geneva, Switzerland, 2000; pp. 1-134.

19. Missmer, S.A.; Suarez, L.; Felkner, M.; Wang, E.; Merrill, A.H., Jr.; Rothman, K.J.; Hendricks, K.A. Exposure to fumonisins and the occurrence of neural tube defects along the Texas-Mexico border. Environ. Health Perspect 2006, 114, 237-241. [CrossRef] [PubMed]

20. International Agency for Research on Cancer (IARC). Toxins derived from Fusarium graminearum, F. culmorum and F. crookwellense: Zearalenone, Deoxynivalenol and Fusarenone X. In Naturally Occurring Substances: Food Items and Constituents, Heterocyclic Aromatic Amines and Mycotoxin; Monogr Eval Carcinog Risks Hum: Lyon, France, 1993; Volume 56, pp. 397-445.

21. Kuiper-Goodman, T.; Scott, P.M.; Watanabe, H. Risk assessment of the mycotoxin zearalenone. Regul. Toxicol. Pharmacol. 1987, 7, 253-306. [CrossRef]

22. Liu, Q.; Wang, Y.J.; Gu, J.H.; Yuan, Y.; Liu, X.Z.; Zheng, W.L.; Huang, Q.Y.; Liu, Z.P.; Bian, J.C. Zearalenone inhibits testosterone biosynthesis in mouse Leydig cells via the crosstalk of estrogen receptor signaling and orphan nuclear receptor Nur77 expression. Toxicol. Vitro. 2014, 28, 647-656. [CrossRef] [PubMed]

23. Zinedine, A.; Soriano, J.M.; Molto, J.C.; Manes, J. Review on the toxicity, occurrence, metabolism, detoxification, regulations and intake of zearalenone: An oestrogenic mycotoxin. Food Chem. Toxicol. 2007, 45, 1-18. [CrossRef] [PubMed]

24. McCormick, S.P.; Stanley, A.M.; Stover, N.A.; Alexander, N.J. Trichothecenes: From simple to complex mycotoxins. Toxins 2011, 3, 802-814. [CrossRef] [PubMed]

25. Ueno, Y.; Sato, N.; Ishii, K.; Sakai, K.; Tsunoda, H. Biological and chemical detection of trichothecene mycotoxins of Fusarium species. Appl. Microbiol. 1973, 25, 699-704. [PubMed]

26. International Agency for Research on Cancer (IARC). Toxins derived from Fusarium sporotrichioides: T-2 toxin. In Naturally Occurring Substances: Food Items and Constituents, Heterocyclic Aromatic Amines and Mycotoxin; Monogr Eval Carcinog Risks Hum: Lyon, France, 1993; Volume 56, pp. 467-489.

27. Wan, D.; Wang, X.; Wu, Q.; Lin, P.; Pan, Y.; Sattar, A.; Huang, L.; Ahmad, I.; Zhang, Y.; Yuan, Z. Integrated Transcriptional and Proteomic Analysis of Growth Hormone Suppression Mediated by Trichothecene T-2 Toxin in Rat GH3 Cells. Toxicol. Sci. 2015. [CrossRef] [PubMed]

28. Pestka, J.J. Deoxynivalenol: mechanisms of action, human exposure, and toxicological relevance. Arch. Toxicol. 2010, 84, 663-679. [CrossRef] [PubMed]

29. Brenner, S. The genetics of Caenorhabditis elegans. Genetics 1974, 77, 71-94. [PubMed]

30. Anderson, G.L.; Boyd, W.A.; Williams, P.L. Assessment of sublethal endpoints for toxicity testing with the nematode Caenorhabditis elegans. Environ. Toxicol. Chem. 2001, 20, 833-838. [CrossRef] [PubMed]

31. Boyd, W.A.; McBride, S.J.; Rice, J.R.; Snyder, D.W.; Freedman, J.H. A high-throughput method for assessing chemical toxicity using a Caenorhabditis elegans reproduction assay. Toxicol. Appl. Pharmacol. 2010, 245, 153-159. [CrossRef] [PubMed]

32. Boyd, W.A.; Smith, M.V.; Freedman, J.H. Caenorhabditis elegans as a model in developmental toxicology. Methods Mol. Biol. 2012, 889, 15-24. [PubMed]

33. Graves, A.L.; Boyd, W.A.; Williams, P.L. Using transgenic Caenorhabditis elegans in soil toxicity testing. Arch. Environ. Contam. Toxicol. 2005, 48, 490-494. [CrossRef] [PubMed]

34. Leung, M.C.; Williams, P.L.; Benedetto, A.; Au, C.; Helmcke, K.J.; Aschner, M.; Meyer, J.N. Caenorhabditis elegans: An emerging model in biomedical and environmental toxicology. Toxicol. Sci. 2008, 106, 5-28. [CrossRef] [PubMed]

35. Anderson, J.L.; Reynolds, R.M.; Morran, L.T.; Tolman-Thompson, J.; Phillips, P.C. Experimental Evolution Reveals Antagonistic Pleiotropy in Reproductive Timing but Not Life Span in Caenorhabditis elegans. J. Gerontol. A Biol. Sci. Med. Sci. 2011, 66, 1300-1308. [CrossRef] [PubMed] 
36. Kaletta, T.; Hengartner, M.O. Finding function in novel targets: C. Elegans as a model organism. Nat. Rev. Drug Discov. 2006, 5, 387-398. [CrossRef] [PubMed]

37. Burden, N.; Chapman, K.; Sewell, F.; Robinson, V. Pioneering better science through the 3Rs: An introduction to the national centre for the replacement, refinement, and reduction of animals in research (NC3Rs). J. Am. Assoc. Lab. Anim. Sci. 2015, 54, 198-208. [PubMed]

38. Singh, J. The national centre for the replacement, refinement, and reduction of animals in research. J. Pharmacol. Pharmacother. 2012, 3, 87-89. [PubMed]

39. Middendorf, P.J.; Dusenbery, D.B. Fluoroacetic acid is a potent and specific inhibitor of reproduction in the nematode Caenorhabditis elegans. J. Nematol. 1993, 25, 573-577. [PubMed]

40. Luder, H.U. Onset of human aging estimated from hazard functions associated with various causes of death. Mech. Ageing Dev. 1993, 67, 247-259. [CrossRef]

41. Meyer, D.; Williams, P.L. Toxicity testing of neurotoxic pesticides in Caenorhabditis elegans. J. Toxicol. Environ. Health B Crit. Rev. 2014, 17, 284-306. [CrossRef] [PubMed]

42. Dhawan, R.; Dusenbery, D.B.; Williams, P.L. Comparison of lethality, reproduction, and behavior as toxicological endpoints in the nematode Caenorhabditis elegans. J. Toxicol. Environ. Health A 1999, 58, 451-462. [PubMed]

43. Williams, P.L.; Anderson, G.L.; Johnstone, J.L.; Nunn, A.D.; Tweedle, M.F.; Wedeking, P. Caenorhabditis elegans as an alternative animal species. J. Toxicol. Environ. Health A 2000, 61, 641-647. [CrossRef] [PubMed]

44. Leung, M.C.; Goldstone, J.V.; Boyd, W.A.; Freedman, J.H.; Meyer, J.N. Caenorhabditis elegans generates biologically relevant levels of genotoxic metabolites from aflatoxin $\mathrm{B}_{1}$ but not benzo[a]pyrene in vivo. Toxicol. Sci. 2010, 118, 444-453. [CrossRef] [PubMed]

45. Gowrinathan, Y.; Pacan, J.C.; Hawke, A.; Zhou, T.; Sabour, P.M. Toxicity assay for deoxynivalenol using Caenorhabditis elegans. Food Addit. Contam. Part A 2011, 28, 1235-1241. [CrossRef] [PubMed]

46. McKean, C.; Tang, L.; Billam, M.; Tang, M.; Theodorakis, C.W.; Kendall, R.J.; Wang, J.S. Comparative acute and combinative toxicity of aflatoxin $\mathrm{B}_{1}$ and $\mathrm{T}-2$ toxin in animals and immortalized human cell lines. J. Appl. Toxicol. 2006, 26, 139-147. [CrossRef] [PubMed]

47. McKean, C.; Tang, L.; Tang, M.; Billam, M.; Wang, Z.; Theodorakis, C.W.; Kendall, R.J.; Wang, J.S. Comparative acute and combinative toxicity of aflatoxin $B_{1}$ and fumonisin $B_{1}$ in animals and human cells. Food Chem. Toxicol. 2006, 44, 868-876. [CrossRef] [PubMed]

48. Fleming, T.; Harrington, D. Counting Processes and Survival Analysis; Wiley: New York, NY, USA, 1991.

49. Yang, J.S.; Nam, H.J.; Seo, M.; Han, S.K.; Choi, Y.; Nam, H.G.; Lee, S.J.; Kim, S. Oasis: Online application for the survival analysis of lifespan assays performed in aging research. PLoS One 2011, 6, e23525. [CrossRef] [PubMed]

50. Schrader, S.; Kramer, S.; Oldenburg, E.; Weinert, J. Uptake of deoxynivalenol by earthworms from Fusarium-infected wheat straw. Mycotoxin Res. 2009, 25, 53-58. [CrossRef] [PubMed]

51. Hemmer, R.M.; Donkin, S.G.; Chin, K.J.; Grenache, D.G.; Bhatt, H.; Politz, S.M. Altered Expression of an L1-Specific, O-Linked Cuticle Surface Glycoprotein in Mutants of the Nematode Caenorhabditis elegans. J. Cell Biol. 1991, 115, 1237-1247. [CrossRef] [PubMed]

52. Dhawan, R.; Dusenbery, D.B.; Williams, P.L. A comparison of metal-induced lethality and behavioral responses in the nematode Caenorhabditis elegans. Environ. Toxicol. Chem. 2000, 19, 3061-3067. [CrossRef]

53. Apfeld, J.; Kenyon, C. Regulation of lifespan by sensory perception in Caenorhabditis elegans. Nature 1999, 402, 804-809. [PubMed]

54. Hosono, R. Sterilization and growth inhibition of Caenorhabditis elegans by 5-fluorodeoxyuridine. Exp. Gerontol. 1978, 13, 369-374. [CrossRef]

(C) 2015 by the authors; licensee MDPI, Basel, Switzerland. This article is an open access article distributed under the terms and conditions of the Creative Commons by Attribution (CC-BY) license (http://creativecommons.org/licenses/by/4.0/). 